\section{The Martin Luther King, Jr. Papers}

Project. Access: www.stanford.edu/ group/King/.

The King Papers Project at Stanford University has numerous resources that are immensely useful for researchers and scholars. Through the cooperative research effort of Stanford University, the Martin Luther King Jr. Center for Nonviolent Social Change, and the Martin Luther King Jr. estate, historical information concerning Martin Luther King Jr. and the civil rights movement is disseminated. Clearly, this extraordinary Web site supports the efforts of the project.

The "Published Documents" area of the site offers works published by the King Papers Project and those written or coedited by Clayborne Carson, director of the project. For example, users can access the full text of selected pages from "The Papers of Martin Luther King, Jr.," a multivolume work in progress. A search engine is provided to assist in searching for documents such as King's speeches, sermons, autobiography, and articles. A comprehensive inventory of King's major sermons, speeches, public statements, public writings, and manuscripts is browsable.

From "Popular Requests," users can quickly access the audio and full text of King's popular letters, speeches, and sermons. However, users will need a player, such as Quicktime or Realmedia, to listen to the files. Several of King's popular quotes and writings on war and peace are available. The major events in King's life are listed chronologically from 1929 to 1955 and can be explored through the "Interactive Flash Chronology." Selected King quotes on education, nonviolence, reconciliation, social justice, and social transformation are provided.

From "About King," users can access a biographical sketch of King. Information on events, people, or places associated with King and the civil rights movement is included in "King Encyclopedia." The excellent "King and the Black Freedom Struggle Chronology, 1896 to 1968 " is found here also.

A link of interest to high school teachers is "Liberation Curriculum," which offers ac- cess to educational materials that address social justice and human rights issues. By becoming a "Liberation Community" member, teachers can access more educational resources and materials not available to the public.

The Martin Luther King, Jr. Papers Project includes other useful pages, such as "Additional Resources," which lists books, children books, audiovisual materials and Web sites for more information on King, and "About the Project."

The site is easily navigable and well organized. It is a valuable resource for users at all levels.-Nancy Allen, University of Soutb Florida at Sarasota-Manatee/New College of Florida, nallen@banshee.sar.usf.edu

Population Reference Bureau. Access:

www.prb.org/.

The Population Reference Bureau (PRB) Web site provides a comprehensive virtual gateway to data and reports on population trends. PRB is a private, not-for-profit organization that has for over 70 years focused on "providing timely and objective population information" in both print and electronic formats. PRB's mission is to disseminate data and to analyze its implications in a nonpartisan manner, while working collaboratively with many worldwide data collection agencies.

Researchers exploring the main page of this site will find a balance of text, graphics and population facts, as well as a centralized column of links that highlight new PRB reports. Most useful to first-time users is the access by topic, available from the left sidebar menu, which includes 16 subjects ranging from education to gender to income and race. Also found here are menu options for the six major regions of the world, and links for quick access to PRB's main focus areas of health, environment, and population trends. A user who selects a topical heading, for example

Joni R. Roberts is associate university librarian for public services and collection development at Willamette University, e-mail: jroberts@willamette.edu, and Carol A. Drost is associate university librarian for technical services at Willamette University, e-mail: cdrost@willamette.edu 
"Income/Poverty," will then get a list of PRB articles, datasheets and reports, most in PDF format, such as State Profiles of Child WellBeing.

These reports frequently include useful graphs and statistics. The authors, in most cases, are academic scholars, health professionals, and foreign government officials.

Other features of interest on this site are the "DataFinder," which offers searching by 95 demographic variables for 220 nations of the world, as well as for the United States and individual states. Students will appreciate the extensive "Glossary of Population Terms," which includes dozens of definitions related to the study of demographics. Other popular and frequently accessed features include the "Graphics Bank" and the "World Population Data Sheet." Researchers can also register for free e-mail updates on population issues, and the site can be accessed in French and Spanish. At the time of this review, the site's search feature was still in progress. The site is relatively current, with PRB noting that updates are provided every three weeks.

The PRB site describes its intended audience as educators, policy makers and the media, but librarians and researchers alike will also find it valuable for its authoritative analysis of dynamic issues and trends in population. The site will be valuable for both domestic and international population study, and is recommended for academic audiences and subject specialists.-Barbara Hillson, George Mason University, bhillson@gmu.edu

\section{Monticello: The Home of Thomas Jefferson.}

Access: monticello.org/.

With 2003 being the bicentennial year of the outset of Merriwether Lewis and William Clark's Corps of Discovery expedition to explore the Louisiana Purchase, there has been much in the way of books, exhibits, and other commemorative events. It seems only right that the person with the idea for the expedition should be recognized for his contribution, and the Monticello site does exactly that. While not the primary focus of this site, the Lewis and Clark expedition and its bicentennial celebration are addressed in a well-developed section dealing with Thomas Jefferson's contributions to the expedition.

The main focus of the site is Jefferson and his home at Monticello. The header bar at the top of the first page provides links to key sections of the site. There is a link to information about Jefferson, which includes a brief biography, a timeline, a day in the life section, and "Jefferson's West," which deals with the Lewis and Clark expedition.

There are also links to information regarding the house, gardens and plantation, visitor information, research and collections, education, and the Jefferson Foundation and the administration of Monticello. While any of these points may be of interest, serious researchers will probably make more use of "Research and Collections," which offers links to publications; reports; programs; collections; the Jefferson Library, including Thomas Jefferson Portal (the library's catalog); and related Web links. One of these links is to the Getting Word: Oral History Project, which records the oral histories of the descendants of Monticello's enslaved African American community.

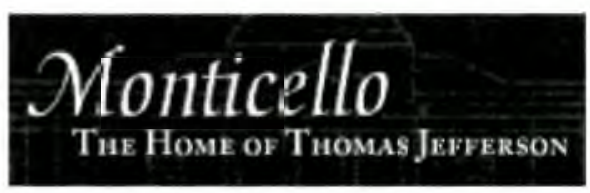

There is also a drop-down box on the right side for browsing points of interest, including agriculture and gardening, architecture and design, books and letters, food and cooking, and science and exploration. Among the topics discussed under food and cooking, for instance, the user will find information on whether Jefferson was a vegetarian, recipes, and the use of dumbwaiters at Monticello.

Netscape users may encounter difficulties loading pages, depending on their version of Netscape. This was not a problem when using Internet Explorer.

This site will be of interest not only to those researching Jefferson, but also to those interested in gardening and horticulture, architecture, the history of American science and technology, and early American history and culture. While much will be made of the Lewis and Clark bicentennial connection, this site offers much beyond that, both to researchers and the merely curious.-Ford Schmidt, Willamette University, fscbmidt@willamette.edu 